\title{
A review of South African Public Healthcare policies addressing Service Delivery for wheelchairs through a Primary Health Care lens
}

\author{
*June Mclntyre, B.OT (US); M.OT (UKZN); PhD candidate (UKZN). \\ https://orcid.org/0000-0002-7726-9249 \\ Retired Occupational Therapist.
}

\author{
Kathlyn Elena Cleland, Nat.Dip.OT (Vona du Toit College of Occupational Therapy); B.OT (UP); M.Ed \\ (UN); PhD (UKZN). https://orcid.org/0000-0002-6829-5592 \\ Registrar, University of KwaZulu-Natal, Durban, South Africa.
}

\author{
Serela Samita Ramklass, B Physiotherapy (UDW); M.Ed (UN); D.ED (UKZN). \\ https://orcid.org/0000-0003-045 I-8942 \\ Senior lecturer, School of Clinical Medicine, College of Health Sciences, University of KwaZulu-Natal, Durban, South Africa.
}

Introduction: In some areas of South Africa, people with impaired mobility are known to have difficulty accessing wheelchairs. This study aimed to critically appraise public healthcare policies addressing service delivery in terms of assistive devices in general, and more specifically wheelchairs within primary health care.

Method: South African public healthcare policies that address assistive device service delivery were identified and thematically analysed using retrospective deductive document analysis. The themes used correspond to the WHO guidelines for the provision of wheelchairs within the context of the guiding principles of primary health care i.e., accessibly, affordability, acceptability, appropriateness, and availability. An analysis was undertaken on how the provision of assistive devices under these principles was addressed.

Results: Three policies were identified addressing assistive device service delivery i.e. The National Rehabilitation Policy, The Policy Framework and Strategy for Disability and Rehabilitation Services in South Africa 2015 - 2020, and the National Health Insurance Policy. The National Rehabilitation Policy addressed the majority of the WHO guiding principles on wheelchair provision. Guidelines for non-discriminatory and evidence-based service delivery and the availability of assistive devices were identified in all the documents. Scant attention was paid to service delivery of assistive devices for people residing in urban or peri-urban areas. There was a paucity of guidance on service delivery to people with impaired mobility who were unable to access health services, those unaware of the services available and those who were not aware of the benefits of an assistive device.

Conclusion: The policies, viewed together, addressed all the WHO guiding principles, although some gaps were observed in each policy. A proposal emanating from this review was that an update of the National Rehabilitation Policy would address these deficiencies.

Keywords: assistive devices, health policy, impaired mobility, disability, rehabilitation

\section{INTRODUCTION}

Assistive devices support the fulfilment of occupational roles' since appropriate and accessible assistive devices promote optimal participation by people with disabilities ${ }^{2}$. The World Health Organisation (WHO) posits that a wheelchair, the most used assistive device for personal mobility, is an essential aid to prevent isolation and restricted access to opportunities such as education and employment ${ }^{3}$. Priorities for governments to meet Sustainable Development Goals should include the provision of assistive devices and formulation of policies guiding these $e^{4}$. Policies can be considered part of the support system in the provision of assistive devices such as wheelchairs', as they guide service providers through an organised framework of principles that informs wheelchair service delivery ${ }^{5}$. The WHO offers a framework that seeks to address the provision of manual wheelchairs ${ }^{6}$. The first step of the framework for the provision of wheelchairs is referral ${ }^{6}$, which implies that the person needing such a device has been able to access a service, where referral for the device such as a wheelchair can be made ${ }^{6}$. A person with an impairment that would benefit from an assistive device should be able to either self-refer (which assumes the person is aware that they can benefit from such a device) or be referred by a health care worker (with a similar assumption) at various levels of service, whether in government, non-governmental or voluntary services ${ }^{1,6}$. Poor policies, amongst other factors, have been identified as restricting the participation of people with disabilities in the healthcare system, leading to inadequate uptake of services ${ }^{7,8}$.

Contextual factors such as inaccessible terrain or buildings (including dwellings), inaccessible or absence of transport ${ }^{8,9}$, vast distances to resources in rural areas and a lack of available assistive devices such as wheelchairs can hamper social engagement and physical function-

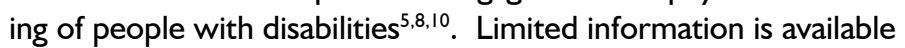
about how these contextual variables are addressed within health 
policies for the delivery of assistive devices such as wheelchairs. While acknowledging that service delivery within the public health space is provided in an inter-sectoral environment and guided by multiple overarching policies (not just those of the Department of Health), guidelines for specific types of service delivery are usually developed from policies developed by a given department ${ }^{\prime \prime}$. This paper, which is part of a larger study, seeks to present an analysis of South African healthcare policies that focus on wheelchair service delivery framed within the guiding principles of primary health care (PHC), as the current dominant model of healthcare in the country. This framing is aligned to the WHO guidelines for the provision of wheelchairs which also uses the principles of $\mathrm{PHC}^{6}$.

\section{LITERATURE REVIEW}

Disability is a contested term; with definitions governed by the conceptual models they are based on. These models have implications for policymaking and service provision ${ }^{12}$. It has been suggested that no model can successfully include all dimensions of disability ${ }^{12}$, as models develop within specific contexts e.g., within the health services, disability studies or human rights movements. The International Classification of Function (ICF) ${ }^{13}$ which can be referred to as a biopsychosocial model, attempts to bridge the gap between the medical and the social models but does not sufficiently take context and culture into account to facilitate access ${ }^{7}$. Culture and context have been identified as facilitators in other areas of occupation such as both basic and instrumental activities of daily living ${ }^{14}$.

A wheelchair user (which will be the term used in this study) can display complex interaction(s) between a variety of factors, which include impairment (ICF body function and structure), and contextual factors i.e., their aspirations as an individual (ICF personal factors), products and technology, the environment, policies, attitudes, and relationships (ICF environmental factors) ${ }^{13}$. The lack of an assistive device such as a wheelchair can affect the ability of a person with a mobility impairment from accessing services such as health, education, and employment, which in turn, can lead to isolation and a cycle of poverty ${ }^{5,11,15,16}$. Statistics often underestimate the prevalence of disability because of inaccurate information collected on disability surveys due to poorly formulated questions and disability measures ${ }^{7}$. The prevalence of mobility impairment in South Africa is about $1 \%$ of the total population ${ }^{17}$. These statistics exclude disabilities in children under the age of five years ${ }^{17}$. All these factors impact on the planning and provision of service delivery.

The joint position paper of the $\mathrm{WHO}$ uses the principles of $\mathrm{PHC}$ to guide the provision of wheechairs ${ }^{3}$. This resonates with South Africa's vision of providing a single unified and equitable healthcare system ${ }^{18,19}$. The guiding principles of service delivery aim at ensuring accessibility (physical, geographic, non-discrimination), affordability (time, finance), acceptability (culture and language, ethical and sensitive staff), appropriateness (evidence-based, available equipment) and availability (infrastructure, staff, function) of healthcare services $^{3,20,21}$. The last decade has seen the move towards service provision in a broader sense, with the use of the eight steps of wheelchair service provision of the WHO (2008), commonly being used as the point of reference. These were drawn up in consultation with a variety of role players ${ }^{6}$.

Service provision is multi-layered and complex, with little published information available on policies and guidelines to identify best practice in wheelchair provision. Publications in this field have tended to focus on the implementation of the policies themselves, or the perceptions of the users of the service ${ }^{22,23}$. A recent publication highlighted the dissatisfaction with wheelchair services by the users in Zimbabwe and recommended that there needed to be good practice guidelines for service delivery, as well as for the management of wheelchair donations ${ }^{24}$. Satisfaction with the service improved with the introduction of the WHO eight-step programme of service delivery ${ }^{24}$. Impediments to wheelchair service delivery may be due to policies and procedures themselves. The providers of wheelchairs are often seen as having power in terms of their position, but there are limits to their autonomy in terms of policies and procedures of the areas in which they practice ${ }^{25}$. In many low-income countries, the availability of assistive devices (also referred to as assistive products or assistive technology ${ }^{26}$ ) is far less than the need ${ }^{27}$. There are gaps in the implementation of the policies in rural areas of South Africa, although the service delivery is in line with the SA national guidelines on provision of assistive devices, the CRPD and the WHO 8 steps $^{22}$. The most positive identified aspect of service delivery was the caring and enthusiastic staff offering the service ${ }^{22}$.

Inconsistencies and poor understanding of $\mathrm{PHC}$ raise unrealistic expectations of service delivery by users of the healthcare system ${ }^{19}$. The complex nature of service delivery means that a 'one size fits all' approach to address needs is unlikely to be adequate. Service providers should be aware of the influence of context on the implementation of policy ${ }^{5,7}$. Context-specific service delivery requires site analyses to be undertaken to ensure that culturally appropriate services are provided through results obtained from monitoring and evaluation ${ }^{7,8,20}$. These services include the placement and role clarification of professional therapy staff and mid-level workers in the provision of assistive devices, which can hamper service delivery if their scope of practice is not appropriately clarified ${ }^{28}$. A South African study reported that the lack of monitoring and evaluation of current public service practices in terms of the delivery of services to people with disabilities affects the implementation of policies ${ }^{8}$. This in turn, can perpetuate human rights violations. Those who need assistive devices such as wheelchairs have the right to access health care services, but, unless there is community outreach, they might be unable to practically access them ${ }^{8,22,28}$. Literature has shown that a good indicator of overall equity in a health system is the access people with disabilities have to health services ${ }^{29}$.

A policy can be defined as "the organisation's stated position on internal or external issues" Republic of South Africa 2020) ${ }^{30: 8}$ Policy reform in South Africa has been driven by a rights-based approach in an attempt to redress the inequities of the past, especially around aspects related to service delivery ${ }^{30}$. The initial document that formed the basis of some of the policies formulated post-1997, was the White paper on an Integrated National Disability Strategy $(\text { INDS })^{31}$. This was updated in 2015 as the White Paper on the Rights of Persons with Disabilities ${ }^{32}$. Neither of these documents was developed within the Department of Health, although they act as transversal policies (i.e., developed within a department but applicable throughout the state services ${ }^{30}$ ).

Best practice in terms of wheelchair service delivery in South Africa is challenged by the complex issues involved in this process of service delivery ${ }^{22}$. However, while acknowledging that service delivery within the public health space is provided in an intersectoral environment, guidelines for specific types of service delivery are usually developed from department-specific policies ${ }^{30}$. This study aimed to identify and analyse the healthcare policies that address access to assistive devices such as wheelchairs within the South African public health system. The research question was: Which factors influence assistive device provision, particularly wheelchairs, within South African healthcare policies? The results derived from 
this analysis will identify the enablers and barriers to wheelchair service delivery from a healthcare policy perspective underpinned by the guiding principles for $\mathrm{PHC}$ and the WHO guidelines for wheelchair service delivery.

\section{Ethical Clearance}

Ethical clearance for the study on which this paper is based was obtained from the University of KwaZulu-Natal, Biomedical Research Ethics Committee (approval no BE327/I5) and the KwaZulu-Natal Department of Health.

\section{METHODS}

A retrospective document analysis was undertaken of current healthcare policies relating to the provision of assistive devices such as wheelchairs, in the public health sector in South Africa.

Document analysis offers a systematic way of evaluating relevant documents to gain an understanding of how the documents address identified issues ${ }^{33}$. This method is used to examine the content of existing documents ${ }^{33}$. Identifying the 'problems' that the document such as a policy seeks to address, is as significant as identifying unarticulated problems, as this affects how they are drafted and evaluated ${ }^{34}$.

Retrospective document analysis is a form of qualitative investigation that examines and interprets the written data to gain an understanding of a phenomenon ${ }^{33}$. The advantage of this method is the non-reactive nature of the data (i.e., the data is not affected by the research process, as it is in written form $)^{33}$. The disadvantage of this method is a possible bias in the selection of the documents used for analysis ${ }^{33}$.

The document analysis was focussed through a lens provided by the principles of $\mathrm{PHC}$ and the WHO guidelines for wheelchair provision. These guided the content and deductive analysis into themes related to accessibility, affordability, acceptability, appropriateness and availability ${ }^{3,21}$ and their sub-themes, within the selected policies. The findings of the thematic analysis were reviewed by two independent researchers against the original policies to ensure validity of results.

An assistive device described by the WHO as "a device, the purpose of which is to maintain or improve an individual's functioning and independence thereby promote their wellbeing" (WHO $2016)^{1: 35}$. The terms assistive device and wheelchair were used interchangeably during the analysis process as wheelchair in the context of rehabilitation and rehabilitation policy is subsumed within the collective category of assistive devices.

The following inclusion criteria guided the selection of policies:

I. Policies dated from 1997, as these were the first published documents following the introduction of the PHC system in South Africa, to 2020.

2. The policy was developed by the National Department of Health of South Africa, as this is currently the authority for the supply of assistive devices such as wheelchairs in the public sector.

3. The policy refers to $\mathrm{PHC}$ principles in terms of service delivery of assistive devices.

4. The policy includes wheelchair or assistive device provision in the heading or body/ text of the document.

Keywords used to search included health policy AND/OR disability AND/OR wheelchair(s) AND/OR mobility device(s) AND/ OR assistive device(s) initially within the South African National Department of Health (www.health.gov.za) and the general government website (www.gov.za) in 2017 when the initial searches were conducted. Currently, the search function in these websites makes it more difficult to access them using this method. The search was further expanded to academic institutions, where the most easily accessible was that of the University of Cape Town. All the documents were available at https://libguides.lib.uct.ac.za/c. php? $g=194637 \& p=5049283$. Searches were conducted for policies published during the period 1997 - August 2020. The identified policies were then downloaded from the links provided. There have been no policies published post-2017 that address assistive device provision.

The following three documents were selected for analysis, as they are the only documents identified as policies by the National Department of Health:

a. The National Rehabilitation Policy, $2000^{36}$ (NRP).

b. The Policy framework and strategy for disability and rehabilitation services in South Africa 2015 - 2020. 2015 $5^{37}$ (FSDRS).

c. The National Health Act (2003), National Health Insurance Policy, $2017^{38}(\mathrm{NHI})$.

The INDS ${ }^{31}$ and the White Paper on the Rights of People with Disabilities ${ }^{32}$, as transversal documents, and the Standardisation of Provision of Assistive Devices in South Africa ${ }^{39}$, which is a guideline rather than a policy, were excluded from the analysis.

The documents were read in their entirety several times to enable the researchers to familiarise themselves with the content. Using deductive analysis, the analysis process identified data that aligned with the broad guiding principles of PHC. The sub-themes further categorise these guiding principles and were identified in the literature $\mathrm{e}^{6,19,20,21}$.

- Accessibility of services with subthemes physical access, geographic access, and non-discrimination.

- Affordability of services with subthemes time and finance.

- Acceptability of services with subthemes of culture and language, and ethical and sensitive staff.

- Appropriateness of services with subthemes evidence-based service and available equipment.

- Availability of services with subthemes infrastructure, staff, and function.

\section{FINDINGS}

Themes and sub-themes were deductively drawn from the policy content and matched to literature $e^{6,19,20,21}$. The findings are summarised in tabular form.

\section{Accessibility of services}

Access, as a multidimensional concept has many diverse definitions, with some including affordable, acceptable, and available services as part of acces ${ }^{20}$. This analysis has chosen to describe access as the potential of the wheelchair user to get to a health care service and to use this service, as this would be where an assistive device would be accessed ${ }^{20,21}$. Three aspects of access were identified in the documents i.e., physical access, relating to the built environment of the health care facility, geographic access, which relates to the proximity of the provider to the user of the service, and non-discrimination relating to equity of the service ${ }^{20}$ (Table I, p85).

\section{Affordability of services}

Affordable services are generally described in terms of both direct and indirect $\operatorname{costs}^{20}$. Direct costs relate to the cost of the services or devices ${ }^{20}$, with indirect costs i.e., those linked to the cost of acquiring the service or device generally measured in terms of travelling costs, excessive travelling or waiting times or lost op- 
Table I: Accessibility of services

\begin{tabular}{|c|c|c|c|}
\hline & NRP & FSDRS & $\mathrm{NHI}$ \\
\hline \multirow[t]{2}{*}{$\begin{array}{l}\text { Physical } \\
\text { access }\end{array}$} & \multirow[b]{2}{*}{ Not addressed } & $\begin{array}{l}\text { Accessible } \\
\text { infrastructure } \\
\text { and transport }\end{array}$ & \multirow[t]{2}{*}{ Not addressed } \\
\hline & & $\begin{array}{l}\text { Access to } \\
\text { health and re- } \\
\text { habilitation at a } \\
\text { single point }\end{array}$ & \\
\hline \multirow{4}{*}{$\begin{array}{l}\text { Geographic } \\
\text { access }\end{array}$} & \multirow{4}{*}{$\begin{array}{l}\text { Locally avail- } \\
\text { able services } \\
\text { at home, in the } \\
\text { community, in } \\
\text { institutions }\end{array}$} & \multirow{2}{*}{$\begin{array}{l}\text { Repairs to as- } \\
\text { sistive devices } \\
\text { (ADs) and } \\
\text { wheelchairs to } \\
\text { be available at } \\
\text { PHC and com- } \\
\text { munity health } \\
\text { clinic (CHC) } \\
\text { level }\end{array}$} & $\begin{array}{l}\text { Access to } \\
\text { services closest } \\
\text { to where } \\
\text { people live }\end{array}$ \\
\hline & & & \multirow{2}{*}{$\begin{array}{l}\text { Planned } \\
\text { transport to be } \\
\text { provided for } \\
\text { the elderly and } \\
\text { people with } \\
\text { disabilities in } \\
\text { inaccessible } \\
\text { areas }\end{array}$} \\
\hline & & \multirow{2}{*}{$\begin{array}{l}\text { Services to be } \\
\text { close to where } \\
\text { people live }\end{array}$} & \\
\hline & & & $\begin{array}{l}\text { Health care } \\
\text { services to be } \\
\text { "portable" to } \\
\text { ensure conti- } \\
\text { nuity of care }\end{array}$ \\
\hline \multirow[t]{2}{*}{$\begin{array}{l}\text { Non- } \\
\text { discrimination }\end{array}$} & $\begin{array}{l}\text { No discrimina- } \\
\text { tion in terms } \\
\text { of age, gender, } \\
\text { disability, race } \\
\text { etc. }\end{array}$ & \multirow{2}{*}{$\begin{array}{l}\text { An integrated } \\
\text { approach } \\
\text { to all health } \\
\text { programmes } \\
\text { through the } \\
\text { continuum } \\
\text { of care at all } \\
\text { levels of care }\end{array}$} & $\begin{array}{l}\text { Should receive } \\
\text { care and } \\
\text { referral at } \\
\text { PHC level }\end{array}$ \\
\hline & $\begin{array}{l}\text { Essential ADs } \\
\text { to be available } \\
\text { at all levels } \\
\text { with equal ac- } \\
\text { cess for all }\end{array}$ & & $\begin{array}{l}\text { Fair and just } \\
\text { health care } \\
\text { system for all }\end{array}$ \\
\hline
\end{tabular}

portunities to earn money ${ }^{20,21}$. Time-related costs to the client are not mentioned when affordable services are considered. In addition to time spent waiting for service appointments and long travelling times have been identified as barriers to use of services by people with disabilities ${ }^{20}$ (Table II, above).

\section{Acceptability of services}

Acceptable services are generally described as being culturally sensitive (e.g., respectful of cultural differences) ${ }^{21}$, offered in a language the clients are familiar with by staff who are ethical and culturally sensitive to the needs of the service users ${ }^{20,21}$. Culture and language are acknowledged as critical issues for acceptable services only in the NRP, with the FSDRS stating that rehabilitation staff need to be 'culturally sensitive ' $^{36,37}$. For this paper, attitudes are included in the collective description of sensitive staff, implying that a positive attitude to a person with a disability would facilitate sensitive behaviour of the service provider ${ }^{40}$. This theme with its subthemes was the most poorly addressed in the documents and was the most difficult to categorise (Table III, above).

\section{Appropriateness of services}

Appropriate services have been described as evidence-based inter-
Table II: Affordability of services

\begin{tabular}{|c|c|c|c|}
\hline & NRP & FSDRS & $\mathrm{NHI}$ \\
\hline Time & Not addressed & Not addressed & Not addressed \\
\hline \multirow{4}{*}{$\begin{array}{l}\text { Finance - } \\
\text { direct costs }\end{array}$} & $\begin{array}{l}\text { Free basic } \\
\text { ADs should be } \\
\text { available }\end{array}$ & & \multirow{4}{*}{$\begin{array}{l}\text { There should } \\
\text { be no "out } \\
\text { of pocket" } \\
\text { expenses }\end{array}$} \\
\hline & $\begin{array}{l}\text { The Universal } \\
\text { Patient Fee } \\
\text { Structure } \\
\text { (UPFS) to } \\
\text { apply }\end{array}$ & \multirow{3}{*}{ Not addressed } & \\
\hline & $\begin{array}{l}\text { Free health } \\
\text { care to chil- } \\
\text { dren under } 6 \\
\text { should include } \\
\text { ADs }\end{array}$ & & \\
\hline & $\begin{array}{l}\text { Dedicated } \\
\text { budgets for } \\
\text { ADs }\end{array}$ & & \\
\hline $\begin{array}{l}\text { Finance - } \\
\text { indirect costs }\end{array}$ & Not addressed & $\begin{array}{l}\text { All levels of } \\
\text { care as close to } \\
\text { where people } \\
\text { live as possible } \\
\text { to decrease } \\
\text { travelling costs }\end{array}$ & $\begin{array}{l}\text { Unaffordable } \\
\text { transport a } \\
\text { barrier to } \\
\text { accessing } \\
\text { services }\end{array}$ \\
\hline
\end{tabular}

Table III: Acceptability of services

\begin{tabular}{|l|l|l|l|}
\hline & NRP & FSDRS & NHI \\
\hline $\begin{array}{l}\text { Culture } \\
\text { and lan- } \\
\text { guage }\end{array}$ & $\begin{array}{l}\text { Language and } \\
\text { cultural differ- } \\
\text { ences need to } \\
\text { be acknowl- } \\
\text { edged and } \\
\text { accepted }\end{array}$ & $\begin{array}{l}\text { Staff need to be } \\
\text { culturally sensitive }\end{array}$ & $\begin{array}{l}\text { Not ad- } \\
\text { dressed }\end{array}$ \\
\hline $\begin{array}{l}\text { Ethical and } \\
\text { sensitive } \\
\text { staff }\end{array}$ & $\begin{array}{l}\text { Cultivation of } \\
\text { a caring ethos } \\
\text { is important }\end{array}$ & $\begin{array}{l}\text { Increase knowledge } \\
\text { and awareness of } \\
\text { health care workers } \\
\text { to change attitudes } \\
\text { to people with dis- } \\
\text { abilities and their } \\
\text { families }\end{array}$ & $\begin{array}{l}\text { Not ad- } \\
\text { dressed }\end{array}$ \\
\hline
\end{tabular}

vention offered by skilled, appropriately trained staff, using available resources and equipment ${ }^{20}$. Evidence is only hinted at in the NRP through reference to $C B R$, the availability of appropriate assistive devices and statistics ${ }^{36}$, which all are rooted in evidence and add to the evidence base (Table IV, 86).

\section{Availability of services}

Available services (Table V, p87) imply a flexible service at a decen-tralised venue that has a suitable infrastructure and available staff equipped with the necessary tools and materials to offer them ${ }^{21}$. Infrastructure is addressed scantily in the reviewed documents, with the NRP envisaging services at local community level, and the $\mathrm{NHI}$ the provision of a "disabled health care infrastructure" at all levels of care, which must include assistive devices ${ }^{36,38}$. The functionality of the available services needs to exhibit flexibility and adaptability in the rendering of these services ${ }^{21}$. Tools and materials need to be available and functioning and the programmes on offer to be suitable ${ }^{21}$. 


\begin{tabular}{|c|c|c|c|}
\hline & NRP & FSDRS & NHI \\
\hline \multirow[t]{4}{*}{$\begin{array}{l}\text { Evidence- } \\
\text { based }\end{array}$} & $\begin{array}{l}\text { Implied through including that the principles } \\
\text { of Community Based Rehabilitation (CBR) } \\
\text { be the approach - supported by secondary } \\
\text { and tertiary rehabilitation }\end{array}$ & $\begin{array}{l}\text { Evidence-based rehabilitation span- } \\
\text { ning all levels of care }\end{array}$ & $\begin{array}{l}\text { Implied through recommending } \\
\text { that comprehensive service includes } \\
\text { rehabilitation and ADs }\end{array}$ \\
\hline & $\begin{array}{l}\text { Implied through the availability of appro- } \\
\text { priate ADs to prevent or arrest effects of } \\
\text { impairment }\end{array}$ & $\begin{array}{l}\text { Appropriate intervention avoids } \\
\text { presenting programmes in silos }\end{array}$ & \multirow{3}{*}{ Rehabilitation forms part of $\mathrm{PHC}$} \\
\hline & \multirow[t]{2}{*}{$\begin{array}{l}\text { Implied through insistence that statistics be } \\
\text { kept of issued ADs - both quantity and type }\end{array}$} & $\begin{array}{l}\text { Referrals and levels of care need to } \\
\text { be provided seamlessly (Integrated } \\
\text { service delivery) }\end{array}$ & \\
\hline & & Grounded in the philosophy of CBR & \\
\hline \multirow{2}{*}{$\begin{array}{l}\text { Available } \\
\text { equipment }\end{array}$} & \multirow{2}{*}{ Not addressed } & \multirow{2}{*}{$\begin{array}{l}\text { ADs to be available based on client's } \\
\text { needs }\end{array}$} & $\begin{array}{l}\text { With the school outreach service, all } \\
\text { grade I learners will be screened and } \\
\text { provided with ADs (i.e., spectacles and } \\
\text { hearing aids) }\end{array}$ \\
\hline & & & $\begin{array}{l}\text { Comprehensive rehabilitation } \\
\text { services must include medical devices } \\
\text { (unspecified) linked to the essential } \\
\text { medicine list (EML) }\end{array}$ \\
\hline
\end{tabular}

Function may be seen as the way users of a service can utilise the service with minimum difficulty ${ }^{20}$. Function is addressed in all three of the documents. The NRP advocates collaborative service provision to decrease the duplication of services, with community follow up forming the most important part of the service ${ }^{36}$. The FSDRS looks at the multi-disciplinary team providing services, especially assistive devices at all levels of care, which should also include the preparation, maintenance, and service of these assistive devices ${ }^{37}$. The $\mathrm{NHI}$ does not address functional issues around rehabilitation or the provision of assistive devices ${ }^{38}$ (Table V, p87).

\section{DISCUSSION}

All the documents analysed are based on the premise of ensuring the human rights of the service user. Within the health services particularly, there has been the intention to promote social justice, amongst other agendas ${ }^{36}$.

\section{Access to services}

Distance to services plays a vital role in health care usage for wheelchair users ${ }^{40}$. Geographic access and non-discrimination are addressed in all three policies, with the common thread that services needed to be rendered as close as possible to where people live. Wheelchair repairs (which form part of the WHO steps for the provision of mobility devices ${ }^{6}$ ) is addressed in terms of geographical access only within the FSDRS ${ }^{37}$. Physical access to services is only addressed in the FSDRS, where specific reference is made to accessibility of infrastructure and transport ${ }^{37}$. The issue of geographic access is poorly explored in literature and similarly, there is a paucity of information about people's perceptions of access, especially when it comes to perceptions about how far health services are to places of residence ${ }^{41}$. No document addresses inaccessible dwellings, which highlights the importance of outreach services in urban and peri-urban areas as well. Only the NRP mentions the availability of essential assistive devices at all levels of care to ensure equal access ${ }^{36}$.

The NHI foresees the provision of transport for people with disabilities and the aged resident in areas that are inaccessible ${ }^{38}$.
However, it does not address the inaccessible terrain or homes that wheelchair users may need to negotiate to reach the designated transport pick-up points or consider residents in cities and towns. The provision of transport envisaged by the $\mathrm{NHI}$ seems to be only to transport people between various levels of care ${ }^{38}$, with little cognisance of the fact that even those that live close to clinics or other health care facilities, might not be able to leave their houses due to inaccessible terrain - e.g., steps leading out of the house to reach a footpath, uneven or no footpaths, steps out of a high-rise building, or to the fact that they may have no wheelchair or an unsuitable wheelchair for use in that terrain ${ }^{15,26}$. There is some recognition that the topography of a region can limit access to services, and that the cost of transport for people with a disability to these services can be prohibitive ${ }^{38}$. Transport will remain a problem in remote rural areas, where there is often no road that allows vehicular access, or in cities, where public transport is not always provided by drivers willing to accommodate wheelchair users ${ }^{9}$. Current outreach to people with disabilities often depends on therapists using their own vehicle, with the legal liabilities attached to this practice, as hospital or clinic transport is not available ${ }^{28}$. Transport may not be made available for use by community health workers ( $\mathrm{CHW}$ ) to visit homes that are in sparsely populated areas $^{28}$, or in township areas where $\mathrm{CHWs}$ must walk to visit community members who might live far apart. This is a limitation within the policies as transport for rehabilitation needs should be included to enable those not able to access services to be reached. Even when there is formal access, community outreach is needed for access to be realised, due to factors such as poor roads, inaccessible homesteads, and transport (including cost) to health care ${ }^{12,20}$.

The access to services by wheelchair users living in city centres in high rise buildings, in suburbs, in outbuildings of formal dwellings, or in informal settlements within cities and towns, is not addressed in any of the documents. These omissions can affect those already disenfranchised by their disability ${ }^{8}$. Denied access due to issues such as the lack of identity documents adds a further barrier, which none of the health policies addresses, as this is the remit of a different government department ${ }^{15}$. This would need to 


\begin{tabular}{|c|c|c|c|}
\hline & NRP & FSDRS & $\mathrm{NHI}$ \\
\hline Infrastructure & At local community level & Not addressed & $\begin{array}{l}\text { Health care infrastructure at all } \\
\text { levels of care including ADs must } \\
\text { form part of a disability health } \\
\text { care service }\end{array}$ \\
\hline \multirow{3}{*}{ Staff } & $\begin{array}{l}\text { Appropriately trained and avail- } \\
\text { able staff }\end{array}$ & \multirow{3}{*}{$\begin{array}{l}\text { A lack of rehabilitation profes- } \\
\text { sional teams hampers service } \\
\text { delivery. }\end{array}$} & \multirow{3}{*}{ Not addressed } \\
\hline & $\begin{array}{l}\text { Appropriate allocation of all } \\
\text { resources (including staff) }\end{array}$ & & \\
\hline & $\begin{array}{l}\text { Must be part of the multidisci- } \\
\text { plinary team (MDT) }\end{array}$ & & \\
\hline \multirow{3}{*}{ Function } & Collaboration & \multirow{3}{*}{$\begin{array}{l}\text { ADs available at all levels, except } \\
\text { central hospitals - clients to be } \\
\text { referred to lower levels of care } \\
\text { for these. }\end{array}$} & \multirow{3}{*}{ Not addressed } \\
\hline & Community follow up & & \\
\hline & Basic ADs at all levels & & \\
\hline
\end{tabular}

be addressed through inter-sectoral collaboration, as many policies and regulations fall outside the health department but do have an impact on the services rendered within the public health space by the rehabilitation staff.

\section{Affordability of services}

Poverty measures generally do not acknowledge the extra cost of disability to meet basic needs such as assistive devices ${ }^{10}$. Policy documents addressing the meeting of needs for people with disabilities are usually not adequate, as there are differing needs related to the area, the individuals involved as service providers and the users of the service. These make turning policy into practice difficult ${ }^{8,42}$. A policy document might need to address this by the addition of a stated position on the direct and indirect cost implications for people with disabilities. The document should for instance, advocate that waiting times should be kept to a minimum, i.e., that either the person is to be seen within an acceptable period, or that another appointment needs to be made if this is not possible. Research has indicated that waiting times commonly stretch up to half a day ${ }^{40}$. The financial aspect of affordable services is addressed with the NRP advocating free assistive devices to be provided to those that qualify, a dedicated budget for assistive devices must be available and that assistive devices need to be charged for according to the Universal Patient Fee Structure ${ }^{34,39}$. This is consistent with the WHO policy brief that advocates the essential inclusion of assistive devices $^{35}$. The FSDRS and the NHI posit that providing services close to where people live will decrease the cost of transport ${ }^{37,38}$. These are in accordance with the WHO recommendations ${ }^{6}$. The $\mathrm{NHI}$ further proposes that there should not be any 'out of pocket' expenses for the user. There is, however, no mechanism referred to that can identify these expenses ${ }^{38}$. It might be useful to identify what these potentially are in each health district, as they would differ. Cross-referencing within policies could aid practitioners in understanding how these policies are linked, as it has been reported that practitioners interpret policies based on local conditions and circumstances ${ }^{8}$. Problems are experienced in countries with similar circumstances to South Africa, but as service delivery models differ for each setting, it is difficult to compare them ${ }^{27}$. The potential for confusion when disability policies are situated in different ministries is huge, and basic assumptions underlying policy documents are some of the reported problems in implementing a consistent service ${ }^{43,44,45}$. The provision of free assistive devices through government services or via donations, have created problems such as inappropriate wheelchairs being provided, causing negative effects for recipients in terms of costs 22,46 .

\section{Acceptability of services}

Considering a person's language and culture can aid the identification of difficulties experienced by the person ${ }^{46}$ and being culturally responsive i.e., being receptive to building a relationship with the person ${ }^{47}$. It is suggested that cultural sensitivity (also referred to as culture consciousness or cultural responsiveness) would involve the identification of the person's personal goals and their desired outcomes with the use of the $A D^{16}$. Attitudes impact on both the nature and outcome of the interactions ${ }^{16}$. The focus on ethical and sensitive staff are addressed in the NRP and the FSDRS poli$\operatorname{cies}^{36,37}$. The NRP specifically advocate a caring ethos and a positive attitude for staff, with the FSDRS advocating increasing knowledge and awareness to change attitudes of health care workers towards people with disabilities and their families ${ }^{36,37}$. Positive attitudes of staff to people with disabilities have been identified as one way of decreasing the exclusion and disempowerment of people with disabilities $^{40}$. It has been documented that the negative attitudes of healthcare workers are a barrier to accessing health care by people with disabilities ${ }^{48}$. However, this is not explicitly addressed in the selected documents. Although attitudes cannot be laid down in policy, encouraging positive experiences for people with disabilities with health services should be part of the stated aims of a policy.

The FSDRS advocates the establishment of a complaints register to identify "disability-related complaints" ${ }^{37}$. Research indicates that service users in South Africa and elsewhere are dissatisfied with services rendered regarding assistive devices ${ }^{22}$, which include the poor fit of the device, frequent repairs needed for wheelchairs and that their needs are not considered or understood by the service providers which might be considered a disability-related complaint $^{24,45}$.

\section{Appropriateness of services}

The NRP extensively addresses the provision of assistive devices, highlighting appropriateness of the assistive device to the user to limit the effects of disability ${ }^{36}$. The NRP and the FSDRS speak to the provision of services using the philosophy and principles of CBR at PHC level, supported by higher levels of rehabilitation where appropriate $^{36,37}$. The FSDRS specifically advocates integrating services for best results with care, and includes referrals, provided seamlessly throughout the various levels (excluding central hospital level) ${ }^{37}$. 
Health systems research however, indicates that health care delivery still tends to happen in silos, especially between the clinics and the hospitals, which could be remedied by integrated services ${ }^{11,16,45}$. The $\mathrm{NHI}$ envisages that rehabilitation will be part of $\mathrm{PHC}$, and includes assistive devices, which it foresees will be included in the essential medicine list (EML) - although the existing lists exclude assistive devices $^{38}$. The provision of assistive devices could be better served through adapting the WHO's Priority Assistive Products List (APL) for use in South Africa use, and through including this in the policy, rather than the inclusion in the $\mathrm{EML}^{35}$, which is in keeping with the $\mathrm{WHO}$ that have and EML and the APL as separate documents ${ }^{26}$.

Unreliable and unavailable resources hamper appropriate service delivery in many rural and urban areas $^{49}$, but these are systemic problems and cannot be addressed in a policy document. Available assistive devices are addressed in all the documents under review, with the NRP and the FSDRS speaking to the availability of assistive devices based on the needs of, or being appropriate to, the client ${ }^{36,37}$. The $\mathrm{NHI}$ speaks about screening of school children for the provision of necessary assistive devices, but only specify spectacles and hearing aids ${ }^{38}$, excluding screening for mobility devices.

\section{Availability of services}

Available services, either generally or service-specific, can vary over time and needs to be monitored ${ }^{50}$. Additionally, community service officers (CSOs) such as physiotherapists and occupational therapists (who may change annually) are often not immediately trusted, as trust takes time to build in communities ${ }^{49}$. Services, particularly in terms of continuity, will therefore be affected in those areas where services are provided exclusively by $\mathrm{CSO}^{49}$.

Staffing has been identified as having a significant effect on wheelchair service delivery, particularly in rural areas ${ }^{22}$. Staff shortages lead to long waiting periods, resulting in people with disabilities tending not to use the services ${ }^{29}$, yet these shortages are only addressed in the NRP and the FSDRS ${ }^{36,37}$. The NRP emphasises the importance of skilled, experienced staff to optimally ensure costeffective services ${ }^{36}$. This is in keeping with research that addresses knowledgeable providers ${ }^{22,45}$. Appropriately allocated members of staff should be part of the PHC team ${ }^{36}$. The FSDRS highlights the effects of a lack of a rehabilitation team in service delivery but does not foresee rehabilitation professionals working at clinic level, only within the hospital setting ${ }^{37}$. This is contrary to the $\mathrm{NHI}$ proposals ${ }^{38}$. The FSDRS suggests the provision of "minor" assistive devices (such as walking sticks and crutches) and that the repair of assistive devices be available at clinic level ${ }^{37}$.

\section{CONCLUSION}

Wheelchair provision is described as a complex rehabilitation intervention. The policies viewed together, address all the guiding principles of PHC for service delivery but when considered individually, they display gaps. The NRP is historically the oldest document addressing the provision of assistive devices and, although not revised or updated, it responds to all five components of $\mathrm{PHC}^{28}$. It therefore seems to be the most comprehensive in terms of assistive device provision at the PHC level. The documents all address non-discriminatory evidence-based service provision, with access to assistive devices. The most poorly addressed issues were that of language and culture as part of acceptable service delivery, and a basic assumption that all health care services are physically wheelchair accessible. There are no concrete plans to coordinate the services, which all these documents acknowledge in the respective preambles and introductions as being a problem for service delivery. There is scant guidance on how assistive devices form part of the service delivery process. By addressing the gaps in the NRP and updating the document, the missing elements could be encompassed within one policy document, making this the golden standard for service delivery in terms of assistive devices (such as wheelchairs) within the South African public health sector. It is important that the policy adequately guides service delivery to the most marginalised members of the population of South Africa.

\section{LIMITATIONS AND RECOMMENDATIONS}

Only documents of the Department of Health of South Africa were analysed, which might imply the perpetuation of the medical model, but it remains the main guide for the distribution of wheelchairs through government services. It would enhance the policy environment if a similar study were undertaken for documents of other government departments such as the Department of Social Development, Department of Basic Education, Department of Higher Education, Department of Public Works, Department of Labour, Department of Co-operative Governance and Traditional Affairs. Similarly, analysing the documents for other more specialised assistive devices would enhance the understanding of how these documents become facilitators or barriers to access.

\section{AUTHOR CONTRIBUTIONS}

June Mclntyre was the primary researcher responsible for the project design, data collection and analysis. Serela Ramklass and Kathlyn Cleland supervised the project and contributed substantially to the writing of the paper.

\section{REFERENCES}

I. Arthanat S, Simmons CD, Favreau M. Exploring occupational justice in consumer perspectives in assistive technology. Canadian Journal of Occupational Therapy. 201 2; 79:309-3 19. Accessed August 2020. https://doi.org/I0.2182/CJOT.20I2.79.5.7

2. World Federation of Occupational Therapists. Position statement: occupational therapy and assistive technology. 2019. Accessed September 2020. https://www.wfot.org/resources/occupationaltherapy-and-assistive-technology

3. World Health Organisation. Joint position paper on the provision of mobility devices in less-resourced settings. Malta: WHO. 20I I Accessed August 2020. https://www.who.int/disabilities/publications/ technology/jpp_final.pdf

4. Tebbutt E, Brodmann R, Borg J, MacLachlan M et al. Assistive products and the Sustainable Development Goals (SDGs). Globalization and Health. 2016; 12:79 Accessed August 2020

https://doi.org/10.1 186/s 12992-016-0220-6

5. Kamaraj D C, Bray N, Rispin K, Kankipati P, Pearlman J, Borg J. A conceptual framework to assess effectiveness in wheelchair provision. African Journal of Disability. 2017; 6(0)a355. Accessed August 2020. https://doi.org/10.4102/ajod.v6i0.355

6. World Health Organisation. Guidelines on the provision of manual wheelchairs in less resourced settings. Malta: WHO. 2008. Accessed August 2020.

https://www.who.int/publications/i/item/978924I547482

7. Lang R, Kett M, Groce N, Trani J-F. Implementing the United Nations Convention on the rights of persons with disabilities: principles, implications, practice and limitations. ALTER. European Journal of Disability research. 20I I; 5:206-220. Accessed August 2020. https://doi.org/10.1016/j.alter.201 I.02.004

8. Neille J, Penn C. Beyond physical access: a qualitative analysis into the barriers to policy implementation and service provision expe- 
rienced by persons with disabilities living in a rural context. Rural and Remote Health. 2015; I5. Accessed June 2020.

http://www.rh.org.au/journal/article/3332

9. Lister HE, Dhunpath R. The taxi industry and transportation for people with disabilities: implications for universal access in a metropolitan municipality. Transformation: Critical perspectives in Southern Africa. 2016; 9028 - 48. Accessed June 2020.

https://muse.jhu.edu/article/620235

10. Palmer M. Disability and poverty: a conceptual review. Journal of Disability Policy Studies. 20 I ; 2 I (4): 210 - 218. Accessed July 2020. https://doi.org//0.1 177/1044207310389333

II. Dayal H. Provision of rehabilitation services within the district health system - the experience of rehabilitation managers in facilitating this right for people with disabilities. South African Journal of Occupational Therapy. 2010; 40(I):22 - 26. Accessed June 2020. http://www.scielo.org.za/pdf/sajot/v40n l/06.pdf

12. Berghs M, Atkin K, Graham H, Hatton C, Thomas C. Implications for public health research of models and theories of disability: a scoping study and evidence synthesis. Public Health Research. 2016; 4(8). Accessed September 2020. https://doi.org//0.33 10/phr04080

13. World Health Organisation. International Classification of Functioning, Disability and Health (ICF). 200I. WHO library cataloguing- in - publication data, Geneva. Accessed a March 2020.

http://www.who.int/classifications/icf/en/

14. McAdam J C, Franzsen D, Casteleijn D, Identification of occupations in a South African rural less-resourced community. Journal of Occupational Science. 201 9; 23(3) 379-393. Accessed August 2020. https://doi.org/10.1080/14427591.2019.1614476

I5. Grut L, Mji G, Braathen S H, Ingstad B. Accessing community health services: challenges faced by poor people with disabilities in a rural community in South Africa. African Journal of Disability. 20I2; I(I). Accessed June 2020. https://doi.org/10.4102/ajod.vlil.19

16. Sherry K. Disability and rehabilitation: Essential considerations for equitable, accessible and poverty-reducing healthcare in South Africa. South African Health Review. 2015; 2015(1):89-99. Accessed September 2020. https://journals.co.za/doi/10.10520/EJCI89294

17. Statistics South Africa. Census 201 I: Profile of persons with disabilities in South Africa. 2014. Report number 03-01-59. Pretoria, South Africa. Accessed June 2020. http://www.statssa.gov.za

18. Republic of South Africa: Department of Health, 1997. White paper for the transformation of the health system in South Africa. Notice 667 of 1997. Accessed September 2020. https://www.gov.za/sites/ default/files/gcis_document/201409//79/0gen6670.pdf

19. Dookie S, Singh S. Primary health services at district level in South Africa: a critique of the primary health care approach. BMC Family Practice. 2012; 13(67). Accessed July 2020.

https://doi.org/10.1 186/I47I-2296-13-67

20. Russel D J, Humphreys J S, Ward B, Chrisholm M, Buykx P, McGain $M$, Wakerman J. Helping policy-makers address rural health access problems. Australian Journal of Rural Health. 2013; 21:61 - 71 . Accessed June 2020. https://doi.org//0.1 I I I/ajr. 12023

2I. Levesque J-F, Harris MF, Russel G. Patient-centred access to health care: conceptualizing access at the interface of health systems and populations. International Journal for Equity in Health 20 I3; I2(I8). Accessed June 2020. https://dx.doi.org/10.1 186\%2FI475-9276-12-18

22. Visagie S, Scheffler E, Schneider M. Policy implementation in wheelchair service delivery in a rural South African setting. African Journal of Disability. 2013; 2(I). Accessed June 2020.

http://dx.doi.org/10.4102/ajod.v2il.63

23. Williams E, Hurwitz E, Obaga I, Onguti B, Rivera A, et al Perspectives of basic wheelchair users on improving their access to wheelchair services in Kenya and Philippines: a qualitative study. BMC International Health and Human Rights 2017 17:22. Accessed June 2020. https://doi.org/10.1I86/s I2914-017-0130-6

24. Visagie S, Mlambo T, Van der Veen J, Nhunzvi C, Tigere D, Scheffler E. 'Is any wheelchair better than no wheelchair? A Zimbabwean perspective'. African Journal of Disability. 20I 5; 4(I). Accessed June 2020. http://dx.doi.org/10.4102/ajod.v4il.20I.

25. Mortenson WB, Miller WC. The wheelchair procurement process: Perspectives of clients and prescribers. Canadian Journal of Occupational Therapy. 2008; 75(3): I67- I 75. Accessed September 2020. https://doi.org/10.1 I77\%2F000841740807500308

26. MacLachlan M, Banes D, Bell D, Borg J, Donnelly B, et al. Assistive technology policy: a position paper from the first global research, innovation, and education on assistive technology (GREAT) summit. Disability and Rehabilitation: Assistive technology. 2018; 13(5):454466. Accessed September 2020.

https://doi.org/10.1080/17483107.2018.1468496

27. Jefferds AN, Beyene NM, Upadhyay N, Shoker P, Pearlman JL, Cooper RA, Wee J. Current State of Mobility Technology Provision in Less- Resourced Countries. Physical Medicine and Rehabilitation Clinics. 2010; 2 I (I): 22I-242. Accessed September 2020. https://doi.org/10.1016/j.pmr.2009.07.01।

28. Bateman C. "One size fits all” health policies crippling rural rehabtherapists. South African Medical Journal. 2012; 102(4):200 - 206. Accessed September 2020.

http://www.samj.org.za/index.php/samj/article/view/5806

29. MacLachlan M, Mannan H, McAuliffe E. Access to health care of persons with disabilities as an indicator of equity in health systems. Open Medicine. 201 I; 5(1):10-12. Accessed September 2020. https://www.ncbi.nlm.nih.gov/pmc/articles/PMC32058I0/pdf/ OpenMed-05-el0.pdf

30. Republic of South Africa: The Presidency. National policy development framework 2020. Pretoria. Pp 8. Accessed January 2021. https://www.gov.za/documents/national-policy-developmentframework-2020-2-dec-2020-0000

31. Republic of South Africa: Office of the deputy president. White paper: Integrated national disability strategy. 1997. Accessed June 2020. https://www.gov.za/sites/default/files/gcis_document/201409/ disability2.pdf

32. Republic of South Africa: Department of Social Development, South Africa. White paper on the rights of persons with disabilities. 2015. Accessed June 2020. https://www.gov.za/sites/default/files/ gcis_document/201603/39792gon230.pdf

33. Bowen G A. Document analysis as a qualitative research method. Qualitative research journal. 2009; 9(2):27 - 40. https//:doi.org/10.3316/QRJ0902027

34. Bacchi C. Problematizations in health policy: questioning how "problems" are constituted in policies. SAGE Open. 2016; 1-16. Accessed August 2020. https://doi.org/10.1 I 77/2 I 58244016653986

35. World Health Organisation. Priority assistive products list. 2016. Accessed June 2020. https://apps.who.int/iris/handle/ I0665/207694

36. Republic of South Africa: Department of Health. National Rehabilitation policy: rehabilitation for all. 2000. Accessed August 2020. https://libguides.lib.uct.ac.za/c.php?g= 194637\&p=5049283

37. Republic of South Africa: Department of Health. Framework and strategy for disability and rehabilitation services in South Africa 2015 - 2020. 20I5. Accessed August 2020.

https://libguides.lib.uct.ac.za/c.php?g = 194637\&p=5049283

38. Republic of South Africa: Department of Health. National health act, 2003. National health insurance policy. Towards universal health 
coverage. 2017. Accessed August 2020.

https://libguides.lib.uct.ac.za/c.php?g= 194637\&p=5049283

39. Republic of South Africa: Department of Health. Standardisation of Provision of Assistive Devices in South Africa. A guideline for use in the public sector. 2003. Accessed August 2020.

https://libguides.lib.uct.ac.za/c.php?g $=1$ 94637\&p $=5049283$

40. Vergunst R, Swartz L, Mji G, MacLachlan M, Mannan H. 'You must carry your wheelchair' - barriers to accessing healthcare in a South African rural area. Global Health Action. 2015; 8. Accessed June 2020. https://doi.org//0.3402/gha.v8.29003

4I. Eide AH, Dyrstad K, Munthali A, Van Rooy G, Braathen SH, Halvorsen T, Persendt F, Mvula P, Rød JK. Combining survey data, GIS and qualitative interviews in the analysis of health service access for persons with disabilities. BMC International Health and Human Rights. 2018; 18(26). Accessed September 2020. https://doi.org/I0.1186/s12914-018-0166-2

42. Mji G, Chappell P, Statham S, Mlenzana N, Goliath C, de Wet C, Rhoda A. Understanding the current discourse of rehabilitation with reference to disability models and rehabilitation policies for evaluation research in the South African setting. South African Journal of Physiotherapy. 2013; 69(2):4-9. Accessed June 2020. https://doi.org/10.4102/sajp.v69i2.22

43. Aldersey HM, Turnbull HR. The united republic of Tanzania's national policy on disability: a policy analysis. Journal of Disability Policy Studies. 20I I. XX(X) I-I0. Accessed September 2020. https://doi.org/10.1 I77\%2FI0442073। I397877

44. Shumba TW, Moodley I. review of policy and legislative framework for disability services in Namibia. South African Journal of Physiotherapy 74(I) a399. 2018. Accessed September 2020.

https://doi.org/10.4102/sajp.v74il.399

45. Cruz DMC, Emmel MLG, Manzini MG, Mendes PVB. Assistive technology accessibility and abandonment: challenges for occupational therapists. The Open Journal of Occupational Therapy 4(I) 2016. Accessed September 2020. https://doi.org/10.15453/2168-6408.1166

46. Pascoe M, Mahura O, Dean J. Health resources for south Africa: a scoping review. Health SA Gesondheid 25(0) 2020. Accessed January 2021. https://doi.org/10.4102/hsag.v25i0.1378

47. Muñoz JP. Culturally responsive caring in occupational therapy. Occupational Therapy International 2007. 14(4):256-280. Accessed September 2020. https://doi.org//0.1002/oti.238

48. Mannan, H., Amin, M., MacLachlan M. \& the EquitAble Consortium. (20II). The EquiFrame Manual: A tool for Evaluating and Promoting the Inclusion of Vulnerable Groups and Core Concepts of Human Rights in Health Policy Documents. Dublin: Global Health Press. Accessed September 2020. https://www.unescap.org/sites/default/ files/EquiFrame\%20Manual_May19_20II.pdf

49. Maart S, Jelsma J. Disability and access to health care - a community-based description study. Disability and Rehabilitation. 2014; 36(I8): 1489 - 1493. Accessed August 2020.

https://doi.org/10.3109/09638288.2013.807883

50. Fusheini A, Eyles J. Achieving universal health coverage in South Africa through a district health system approach: conflicting ideologies of health care provision. BMC Health Services Research. 2016; 16:558. Accessed July 2020.

https://doi.org/10.1186/s|2913-016-1797-4 